
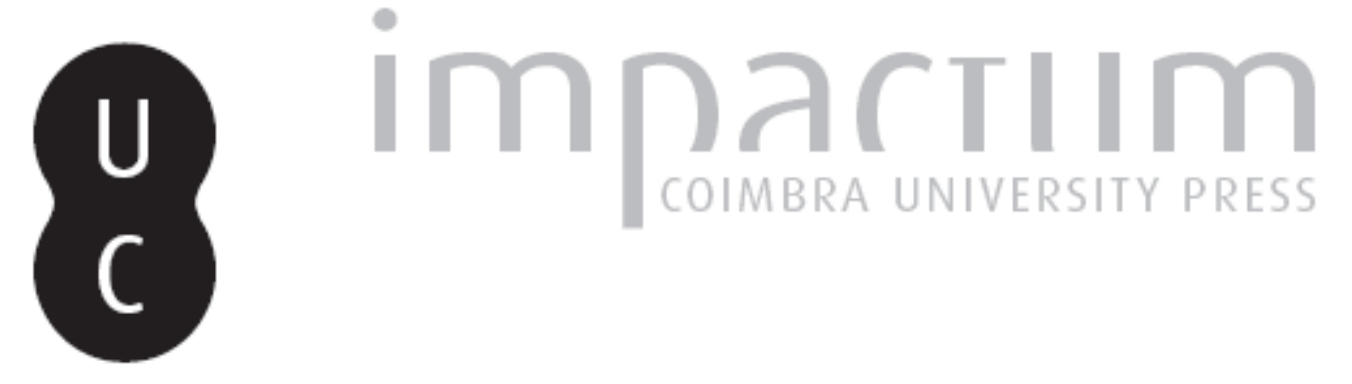

\title{
Aliança estratégica entre Academia e Jornalismo: uma discussão em marcha no Labform
}

\author{
Autor(es): $\quad$ Coelho, Pedro
}

Publicado por: Imprensa da Universidade de Coimbra

URL persistente:

URl:http://hdl.handle.net/10316.2/39018

DOI:

DOI:http://dx.doi.org/10.14195/2183-5462_28_1

Accessed : $\quad$ 26-Apr-2023 13:14:54

A navegação consulta e descarregamento dos títulos inseridos nas Bibliotecas Digitais UC Digitalis, UC Pombalina e UC Impactum, pressupõem a aceitação plena e sem reservas dos Termos e Condições de Uso destas Bibliotecas Digitais, disponíveis em https://digitalis.uc.pt/pt-pt/termos.

Conforme exposto nos referidos Termos e Condições de Uso, o descarregamento de títulos de acesso restrito requer uma licença válida de autorização devendo o utilizador aceder ao(s) documento(s) a partir de um endereço de IP da instituição detentora da supramencionada licença.

Ao utilizador é apenas permitido o descarregamento para uso pessoal, pelo que o emprego do(s) título(s) descarregado(s) para outro fim, designadamente comercial, carece de autorização do respetivo autor ou editor da obra.

Na medida em que todas as obras da UC Digitalis se encontram protegidas pelo Código do Direito de Autor e Direitos Conexos e demais legislação aplicável, toda a cópia, parcial ou total, deste documento, nos casos em que é legalmente admitida, deverá conter ou fazer-se acompanhar por este aviso.

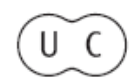




\section{Media 2 Jornalismo}

\section{A DIMENSÃO LABORATORIAL DO ENSINO DO JORNALISMO}




\title{
ALIANÇA ESTRATÉGICA ENTRE ACADEMIA E JORNALISMO \\ UMA DISCUSSÃO EM MARCHA NO LABFORM \\ THE STRATEGIC ALLIANCE BETWEEN ACADEMIA AND \\ JOURNALISM: AN ONGOING DEBATE IN LABFORM
}

\author{
PEDRO COELHO \\ PEDROCOELHO@SIC.IMPRESA.PT \\ UNL/FCSH/DCC \\ SIC TV
}

Resumo

Este artigo parte do debate vivo que se aloja no espaço virtual, acondicionado num blog dedicado à formação académica em jornalismo. A partir dessa discussão levantamos as grandes questões associadas ao percurso ideal para se chegar a uma das mais complexas profissões da humanidade, trespassada, por um lado, pela crise de sustentabilidade do jornalismo, ampliada pelos efeitos da tecnologia digital, por outro, pela indefinição da própria academia. A comunicação adquiriu o estatuto de disciplina académica há quase quatro décadas, mas o jornalismo, uma das áreas nobres do campo, ainda tarda em encontrar um lugar de acolhimento.

\section{Palavras-chave \\ Labform; Jornalismo; Academia; Aliança Estratégica.}

Abstract

This article derives from the vivid debate on a blog about journalism education. That discussion has raised several key questions about the ideal path to enter the journalism career, one of the most challenging crafts. Journalism is suffering a sustainability crises, amplified by digital technology, and concurrently the academia's uncertainty. Communication science has been granted academic status for almost four decades now, but journalism, one of its most noble fields, still struggles to find its place.

KEYWORDS

Labform; Journalism; Academia; Strategic Alliance. 


\title{
ALIANÇA ESTRATÉGICA ENTRE ACADEMIA E JORNALISMO \\ UMA DISCUSSÃO EM MARCHA NO LABFORM \\ THE STRATEGIC ALLIANCE BETWEEN ACADEMIA AND \\ JOURNALISM: AN ONGOING DEBATE IN LABFORM
}

\author{
PEDRO COELHO \\ PEDROCOELHO@SIC.IMPRESA.PT \\ UNL/FCSH/DCC \\ SIC TV
}

\section{Um Jornalismo no Fio da Navalha}

Num mercado fragilizado pela associação do jornalismo às novas tecnologias, a possibilidade de estarmos perante uma ampla distorção dos valores deve ser colocada. Sensacionalismo, interesse humano, infotainment, notícia que vende, comunicadores versáteis, jornalistas tecnológicos multicapacitados, polivalência imposta para redução de custos, jornalistas de mochila às costas, jornalismo de corta e cola, distanciado do lugar da notícia, são apenas alguns dos conceitos, impostos pelo mercado, que se apoderaram do jornalismo e que espelham o grau de distorção.

Na redação portuguesa assistimos a um jornalismo aprisionado por uma crise de sustentabilidade: os jornais reféns da perda de leitores, das quebras de tiragem, da dificuldade em substituir as velhas receitas por outras que proporcionem uma inversão do ciclo; as rádios, mesmo assumindo, ainda, um papel na distribuição quotidiana de informação, vão sendo forçadas, pela crescente irrelevância que acumulam no mapa dos meios, a desinvestir no jornalismo; nas televisões é visível a abertura de brechas no espaço nobre da informação e a interseção, cada vez mais consentida, cada vez mais natural, do jornalismo com as receitas fáceis do entretenimento; na Internet assistimos à dificuldade em delimitar o jornalismo, distinguindo-0: 0 jornalismo permanece um subproduto, feito de corta e cola, que ocupa comunicadores versáteis multicapacitados, mas que não se aproximam do lugar da notícia. A Internet junta vozes dispersas, pensamentos alternativos, abala a visão unitária que os meios tradicionais ampliavam; mas o acesso livre e ilimitado que a define aumenta o risco de interesses particulares, obscuros, conquistarem visibilidade, influenciando opiniões e decisões; serão sempre fontes de ruído impercetíveis que deturpam a ação comunicativa gerada na rede.

É neste contexto que o jornalismo deve afirmar-se filtro da comunicação. Este é pois o tempo da urgência de um jornalismo distinto, de fronteiras precisas, que associe ao faro para desvendar o que é notícia no meio da miríade, o sentido ético para perceber o que o não é; um jornalismo que facilite a comunicação, que a promova; um jornalismo que contribua para iluminar o público, que assuma o compromisso com a sua formação; um jornalismo que comunique com o público, aceitando a sua contribuição no processo de construção da notícia, exercendo sobre os conteúdos gerados pelos cidadãos o exercício de verificação jornalística que torna credíveis as informações, passíveis, portanto, de serem integradas na notícia. 
Todavia, condicionado pelo mercado, que colocou as novas tecnologias ao serviço dos seus interesses, num esforço falhado de maximização da receita, o jornalismo está dependente de um processo de reconstrução.

\section{Reconstruir o Jornalismo a partir da Base: a Formação}

0 processo de reconstrução do jornalismo passa pela recuperação dos valores que o moldam e que o mercado tomou de assalto, mas exige, igualmente, recuperar a finalidade do jornalismo - esse papel de vigilante da democracia que, ao mesmo tempo que deve contribuir para iluminar a ação política, promove a comunicação entre os membros da comunidade, participando na sua formação cívica.

Ora o desafio de reconstrução do jornalismo é de tal forma complexo que o jornalismo, sozinho, não terá condições de Ihe dar resposta. Neste sentido, 0 jornalismo terá de ser reconstruído a partir da sua base de sustentação, a formação de jornalistas; tal pressupõe a própria reconfiguração dessa base. A academia, que deveria estar atenta aos sinais, refletindo sobre a forma de preservar o jornalismo, é um mundo paralelo que julga servir o jornalismo mas que se limita, cada vez mais, a responder às necessidades efémeras do mercado.

Em ambos os lados, jornalismo e academia, subsistem, todavia, zonas de resistência; é nelas que o processo de reconstrução do jornalismo deve assentar âncora.

Por um lado, parcelas significativas da classe jornalística começam a admitir que o jornalismo precisa da crítica para evoluir. Entre 1997 e 2009, o número de jornalistas no ativo com licenciatura ou bacharelato passou de 43,6 para 59,3 por cento (Rebelo, 2011: 81, 82). Nesse período cresceu, igualmente, o número de profissionais de regresso à academia, guiados pela necessidade da valorização pessoal e profissional. Completam estudos de segundo e terceiro ciclo, onde produzem trabalhos de reflexão sobre a ação profissional quotidiana, que Ihes permite distanciarem-se do objeto, aceitando criticá-lo1. Estes factos, por si só, assinalam o peso crescente da academia na profissão. Adelino Gomes, no estudo que fez nas redações dos três canais de televisão portugueses, observou o efeito desse peso nas redações: "Além de mais habilitadas no plano escolar (...) as novas gerações têm-nos oferecido excelentes jornalistas" (2012: 21).

0 investimento na formação académica não oculta, todavia, a crescente perda de autonomia que constitui marca de referência das novas gerações precárias. 0 mercado reforça a contradição que atravessa a história do jornalismo desde 0 século XIX: exige profissionais capacitados, mas, simultaneamente, condicionados pela necessidade de 0 servir.

No lado do jornalismo subsistem, igualmente, expressivos sinais de resistência. São detetados sempre que o jornalismo revela detalhes do quotidiano que, de outra forma, permaneceriam zonas de sombra. Para Adelino Gomes, o jornalismo constrói a sua autonomia sempre que o jornalista, com o seu trabalho, "descreve, vocaliza, mostra um acontecimento, dá voz, pela escrita, pelo microfone, pela ima-

1 No ano de 2009, o número de jornalistas no ativo com mestrado representava 3,4 por cento do total da classe - uma percentagem ainda pouco significativa, mas a representar uma tendência de crescimento relativamente a 2006 - 2,1 por cento. Em 2009, a percentagem de jornalistas no ativo com doutoramento ainda era residual, apenas 0,4 por cento (Rebelo 2011: 81, 82). 
gem, a quem não tem voz, independentemente do seu valor de mercado" (idem, ibidem: 58). É nessa autonomia que se inscreve, aliás, "a relevância do jornalismo" (idem, ibidem: 61).

Numa entrevista que nos concedeu em 2012, Joaquim Fidalgo discorre sobre essa relevância, distinguindo o "cidadão que comete atos de jornalismo" do jornalista, que, proactivamente, "mostra o que ninguém mostra; vai onde ninguém vai". 0 "cidadão que comete atos de jornalismo" é "meramente reativo": "relata porque ia a passar" (apud Coelho, 2015: 588). É neste contexto que José Luís Garcia alerta para as consequências de deixarmos o conhecimento do mundo na dependência "de um quiosque virtual de distribuição", como o Google:

"A menos que se tenha uma absoluta fé nas pessoas (...) o que é melhor em termos de informação não virá à superfície sem um constante trabalho de seletividade, o qual não pode dispensar profissionais competentes e exigentes" (2009: 30).

Pelo peso crescente que vai assumindo, a formação académica transporta um elevado potencial de participação na reconstrução do jornalismo, e esse é um forte sinal de resistência; mas, tal como acontece com o jornalismo, jamais conseguirá fazê-lo sozinha. A solução encaminha-se, de facto, para uma aliança estratégica entre as duas entidades.

Num e noutro lugar, no jornalismo e na academia, é preciso começar do zero.

\section{Reflexos do Fosso entre o Jornalismo e a Academia}

0 primeiro pilar desse amplo processo de reconstrução consiste no estabelecimento de pontes entre a academia e o mercado, que permitam ao jornalismo ultrapassar os constrangimentos criados pelo dilema que o perpassa: servir o púbico, a democracia e o mercado, ou seja, encontrar forma de se tornar social e financeiramente sustentável.

A construção de pontes entre jornalismo e academia pressupõe 0 estabelecimento de uma aliança estratégica entre as duas entidades (Coelho, 2015: 595), 0 que, desde logo, contraria o perfil de ambas. Jornalismo e academia são universos paralelos (Zelizer, 2004: 2), entidades "pouco maleáveis, ciosas dos seus costumes, extremamente vaidosas e pouco recetivas às opiniões externas" (Meditsch: 2004: 26, 27).

Na nossa investigação de doutoramento, sobre a formação académica em jornalismo/comunicação ${ }^{2}$, concluímos que as dificuldades reveladas em promover articulações, no interior dos planos de estudo, entre teoria e prática são consequência direta do fosso que separa a academia do mercado. Essa deficiente articulação promove níveis elevados de abstração - teórica e prática - que, nos casos portugueses analisados, são especialmente apontados criticamente pelos alunos, sobretudo pe-

2 No trabalho de campo estudámos seis licenciaturas na área (Ciências da Comunicação, UNL, Ciências da Comunicação, Jornalismo e Assessoria, UP, Comunicação Social, ESEC, Jornalismo e Comunicação, ULHT, Ciências da Comunicação e da Cultura, ULHT, Ciências da Comunicação, ISMAI), entrevistámos e monitorizámos, ao longo de um ano letivo, o percurso de 67 alunos, incluindo estagiários, e entrevistámos diversos professores de jornalismo. 
Ios estagiários. É certo que o estágio alimenta mais a emoção do que a razão, mas 0 grau crítico com que a maioria dos estagiários, dos seis cursos analisados, avaliou a contribuição da formação académica no desempenho profissional é uma marca clara das barreiras que subsistem entre os dois mundos. Os estagiários passaram seis semestres no curso, mas as opiniões críticas mais acaloradas foram registadas junto de alunos com escassos dias de empresa; para tanto, bastou-lhes ultrapassar 0 impacto (que antecipavam negativo) do primeiro dia.

E certo que a profissão é o futuro do aluno, representando o curso o seu passado, mas os cursos afirmam-se, cada vez mais, como uma máquina de gerar licenciados a quem perdem o rasto, que não cativam, e em quem fomentam avaliações emocionais negativas.

Os percursos de estágio, mesmo nos casos onde o estágio integra o plano curricular, são monitorizados, exclusivamente, pelas empresas que, regra geral, aplicam o mesmo modelo a todos os alunos, o que os deixa muito dependentes do voluntarismo dos diversos editores e coordenadores que, a cada etapa, recebem e orientam os alunos. Esse voluntarismo, e a personalidade dos coordenadores ou editores, acaba por condicionar o percurso do aluno na empresa. Regra geral são percursos solitários, onde o receio de perguntar aos mais velhos, temendo reações negativas, impõe o reforço de laços com os do mesmo grupo: as dúvidas acabam por ser esclarecidas pelos alunos com mais semanas de empresa. No final do percurso, as escolas, onde o estágio permanece no currículo, avaliam os relatórios dos alunos e nenhuma articulação é promovida com a empresa, eventualmente aconselhando alterações no modelo de acolhimento. A escola não faz essa articulação, e as empresas não a solicitam.

Durante a fase de recolha de dados para a nossa investigação de doutoramento, que decorreu no ano letivo de 2010-2011 ${ }^{3}$, assistíamos, ainda, aquilo que classificámos como uma "elevada taxa de rotatividade" dos docentes da variante de jornalismo nos cursos de comunicação e no curso de jornalismo analisados (CoeIho, 2015: 9). A contratação precária de profissionais para as unidades curriculares associadas à ação jornalística impunha-se como norma em quatro dos seis cursos, facto que motivava a rápida desvinculação, imposta pelos cursos ou efetivada pelos próprios contratados. Regra geral, esses docentes, pondo o jornalismo em primeiro plano, mantinham laços frágeis com a academia. Associada ao perfil profissional

3 Os dados foram atualizados no ano letivo de 2012-2013, ainda a tempo de integrarem o nosso estudo. No curso da UNL, dos sete docentes das uc da variante, três tinham contratos de colaboração, acumulando a docência com o jornalismo. No curso de comunicação e jornalismo da Universidade Lusófona de Lisboa 22 dos 36 docentes estavam a tempo parcial, não tendo sido disponibilizados dados sobre o vínculo dos que tinham contratos a 100 por cento. No curso da Lusófona do Porto, os cinco docentes da área, incluindo o diretor, não tinham vínculo ao estabelecimento de ensino. Dois dos três docentes de jornalismo no ISMAI tinham contrato a tempo parcial. 0 diretor do curso acumulava a função com outras atividades profissionais exteriores ao instituto. A estabilidade do corpo docente era regra, apenas, nos cursos da Universidade do Porto e da Escola Superior de Educação de Coimbra. Num e noutro caso apenas um docente se encontrava a tempo parcial. Na ESEC (total de quatro docentes de jornalismo) e na UP (cinco docentes), os docentes envolvidos com a área de jornalismo tinham, todavia, de se desdobrar por diversas uc, o que limitava o tempo para a investigação e o correspondente esforço de consolidação do campo jornalístico. 
destes docentes, a fragilidade dos laços com a academia incentivava o desenvolvimento de programas estritamente práticos, que transformavam a sala de aula numa antecâmara da redação.

Esta sequência de acontecimentos promoveu a subalternização do jornalismo nos planos de estudos face à comunicação. Nos seis cursos analisados, 0 jornalismo não tinha condições para se impor como área de estudo consolidada, a refletir um potencial de participação na reconstrução do jornalismo.

Essa situação é igualmente prejudicada pela barreira entre academia e mercado. Ainda que o mercado esteja a delegar a formação dos novos jornalistas na academia, a manutenção do fosso está a impedir que esta assuma o seu papel na reconstrução do jornalismo. Este cenário de afastamento, que anula o efeito das escassas pontes de contacto que porventura existam, assemelha-se a um entrincheiramento. Por um lado, o mercado que recebe licenciados com cursos na área critica os programas de formação, insistindo na máxima de que estes devem aproximar-se da realidade das empresas de jornalismo; por outro, como observa Johanna Dorer, a partir do exemplo austríaco, os departamentos de comunicação das universidades "detestam abdicar de abordagens mais críticas e teóricas" (2003: 250). Conscientes da importância crescente que vão tendo no mercado, os cursos de jornalismo, sem abdicarem da teoria, foram criando uma dimensão prática abstrata, paralela ao abstracionismo teórico. É nesse sentido que, em diversos cursos, surgiram as unidades curriculares (uc) de prática jornalística, antecâmaras da redação, onde a articulação com quadros concetuais mais abrangentes está ausente dos programas. Essa decisão representa o esforço (aparentemente inglório) dos cursos em responderem, no imediato, às críticas das empresas e dos alunos, mas não resolve o problema de fundo do jornalismo: a necessidade de reconstrução.

Este contexto - planos de estudo onde as dimensões teórica e prática permanecem entrincheiradas - motivou o nosso esforço analítico de estruturação de um novo modelo de formação, cuja base é a articulação entre as duas dimensões e 0 esbatimento do fosso entre a academia e as empresas. Essas aproximações pré-anunciam um outro papel para a academia, definitivamente parceira do jornalismo na prossecução do urgente processo de reconstrução.

Seguimos, a este propósito, o pensamento de Stephen Reese. 0 autor propõe que se descubra a solução para o jornalismo no interior da academia: "Quando 0 prestígio e a credibilidade dos media entram em declínio, a academia é o lugar onde a influência pode ser exercida, em nome da recuperação do respeito" (1999: 77).

\section{Em Defesa de uma Aliança Estratégica entre Jornalismo \\ e Academia: um Debate em Curso no Labform}

A aliança estratégica entre academia e mundo profissional, que preconizamos, abre a porta a um novo lugar de interseção entre a reflexão e a prática; entre o teste e 0 erro; entre velhas e novas receitas, velhos e novos perfis. É um caminho complexo, mas necessário. 0 esteio promotor desse percurso é o esbatimento do fosso entre dois mundos paralelos e distantes. Cada vez mais, essa aliança estratégica entre mundo profissional e academia percorre o pensamento dos atores do processo de formação, jornalistas, académicos, estudantes; algumas dessas vozes enri- 
quecem 0 debate no Labform ${ }^{4}$. Em cada um desses olhares fica registado o desejo de estabelecer pontes, sem que desse aprofundamento de laços resulte a quebra das marcas distintivas de cada um dos mundos.

Adriano Duarte Rodrigues, fundador dos estudos de comunicação em Portugal, defende o estabelecimento de "uma colaboração clara e proveitosa" entre academia e mundo profissional. Para o Professor Jubilado na Universidade Nova de Lisboa essa colaboração será, todavia "tanto mais proveitosa quanto mais respeitadora da autonomia das duas esferas":

"Seria desastroso que a Universidade dependesse dessa ligação e que passasse a definir o perfil da sua formação em função da demanda profissional, tal como seria desastroso que os objetivos empresariais das empresas jornalísticas dependessem dos objetivos universitários. No mundo moderno, qualquer confusão entre a esfera empresarial e o domínio académico é intolerável, porque não respeita a autonomia de cada uma das esferas".

Aníbal Alves, Professor Emérito da Universidade do Minho, considera, exatamente, serem as distinções entre os dois mundos que poderão enriquecer a "desejável" colaboração entre ambos, contribuindo para encontrar "formas de interesse e benefício mútuos". Alves entende, aliás, que esse caminho já está a ser percorrido, podendo, todavia, ser valorizado:

"A recente história do desenvolvimento dos cursos de comunicação e jornalismo oferece já experiências de grande valor para acertar passos que se tenham revelado aquém dos objectivos prosseguidos ou dos que progressivamente vão sendo reformulados. Como é próprio dos saberes e das ciências, bem como de outros projetos humanos".

Carla Baptista, docente da Universidade Nova de Lisboa, antevê a crescente aproximação entre os dois mundos, confiando ser essa a solução que permite "reduzir as distâncias", mas, neste trajeto de entrelaçamento, a professora de jornalismo admite que a universidade sucumba ante a "força dominante e universal do mercado":

"Neste momento, o risco de diluição identitária afeta mais a universidade do que o mercado. A universidade deve lutar para preservar a sua autonomia e a sua definição primordial como espaço de conhecimento, investigação, reflexão e problematização".

Defendemos a definição de um novo mapa de interligações entre academia, cursos de jornalismo/comunicação, e jornalismo que promova o estabelecimento de uma aliança que, de facto, proteja a identidade das duas entidades. No essencial,

4 Depoimentos acessíveis no blog Labform - espaço virtual de interação entre jornalistas e comunidade académica sobre a formação em jornalismo http://www.lasics.uminho.pt/labform/?page_ $\mathrm{id}=74$ 
o modelo que preconizamos estabelece linhas de entrelaçamento internas, entre a coordenação e o corpo docente, com reflexos diretos na abordagem dos saberes que integram o programa de estudos, mas define, igualmente, a consolidação dos laços entre a comunidade académica e a profissional, valorizando a presença dos alunos em ambiente profissional em ações de observação que suscitem a reflexão na sala de aula. 0 modelo requer também o envolvimento da comunidade académica com a comunidade geográfica de acolhimento, incentivando a criação de órgãos de comunicação social próprios que participem no debate e discussão públicas. A um nível mais abrangente, defendemos a institucionalização de compromissos entre os diversos cursos da área, a nível nacional e internacional, com o propósito de alargar a base de discussão do campo da formação, debatendo e promovendo a aplicação das experiências que possam enriquecê-lo (Coelho, 2015: 522-536).

0 debate em curso no Labform prova-nos que a aproximação entre mundo académico e mundo profissional começa a impor-se como base teórica refundadora de qualquer projeto de formação académica na área. Os princípios teóricos refundadores, enunciados nessa discussão, merecem detalhe. É a partir deles que vão surgindo ideias de reestruturação dos estágios e novas propostas concretas de aproximação entre os dois universos paralelos.

\section{A apologia do entrelaçamento}

Gil Ferreira, da Escola Superior de Educação de Coimbra, sublinha a complementaridade entre os dois mundos que torna quase inevitável a "interação estreita" entre ambos, "tanto quanto possível desde o início do ciclo de estudos". Se, como assinala Ferreira, a academia, "enquanto espaço de experimentação e de criação", fornece "os modelos de reflexão e enquadramento da prática profissional", o mundo profissional promove a "aplicação" e "validação" desses modelos de reflexão, confrontando-os com situações concretas que "desafiam" quer os modelos, quer a "experimentação efetuada na academia".

Para Luís Bonixe, o entrelaçamento entre academia e o mundo profissional protegerá 0 aluno na fase de estágio. 0 docente da Escola Superior de Educação de Portalegre considera que 0 sucesso, desse "momento particular de formação em que 0 estudante (ainda) se encontra", dependerá do "equilíbrio" que for possível estabelecer entre a redação e a academia, fruto dessa "ligação mais próxima".

Joaquim Fidalgo, da Universidade do Minho, anseia por "uma ligação muito maior" entre jornalismo e academia, onde o "trânsito" se faça "nos dois sentidos", estabelecendo linhas de "colaboração sistemática e regular" que não se reduzam aos "meros três meses de estágio curricular".

\section{Um outro olhar sobre os estágios curriculares}

0 estágio curricular tem sido, nos cursos que o mantêm no plano de estudos, a única via de interseção do aluno com o mercado de trabalho. Seguindo o trilho de pensamento enunciado por Joaquim Fidalgo, Inês Amaral, da Universidade do Minho, defende uma aproximação crescente do aluno à prática profissional, integrando-se o estágio nesse percurso como "mais um passo na formação dos jornalistas", dando "continuidade" a uma "formação sólida". 
Enaltecendo, igualmente, a importância estratégica dos estágios no percurso do aluno, Carla Baptista, da UNL, alerta-nos para o risco de perdermos o rasto aos alunos quando estes iniciam incursões em ambiente profissional. A docente reclama, por isso, uma maior aproximação entre a universidade e os seus estagiários, devendo aquela monitorizar o desempenho dos alunos através de "gabinetes especializados no acompanhamento dos estágios" e, posteriormente, "na inserção na vida profissional".

Esse exercício ativo de monitorização terá, no entender de Sónia Lamy, da Escola Superior de Educação de Portalegre, no professor/orientador, responsável por esse salto do aluno, 0 seu pilar:

"Se o formador deve ser conhecedor do ambiente no qual o estudante vai estar, também deve ser 0 "treinador" que segue os "saltos" dados no contexto profissional. 0 professor tem de ser um elo entre as instituições no sentido de promover uma integração gradual no novo ambiente e a compreensão dos contextos que ali se encontram".

Em nome do aluno e da sua incursão gradual no mundo profissional, Carlos Camponez destaca a necessária coresponsabilização da empresa. A plena articulação entre orientador académico e orientador profissional, a nomear pela empresa, afirma-se decisiva no "efetivo acompanhamento do aluno". Ainda que o docente da Universidade de Coimbra afirme que o modelo aplicado no curso onde leciona contemple essa articulação, "por vezes os pressupostos", enunciados no protocolo de colaboração, "não são cumpridos de parte a parte", por razões que "escapam aos próprios orientadores".

Jornalistas, académicos e, sobretudo, os alunos manifestam, regra geral, uma insatisfação relativamente aos modelos de estágio e à forma como academia e empresas aligeiram a responsabilidade que ambas assumem quando subscrevem os protocolos. Adelino Gomes, jornalista e investigador, conclui, por isso, que "as más experiências chegam para que se imponha uma revisão séria do sistema, num diálogo entre a escola, as empresas, e a profissão".

\section{A aproximação gradual do aluno ao ambiente profissional}

0 debate no Labform vai dando forma às modalidades de interligação entre a academia e o mundo profissional a partir de modelos, que preveem incursões do aluno na redação, anteriores ao estágio. No essencial, essas propostas seguem a linha de análise que nós próprios traçámos, ao defendermos um processo de integração "faseado e progressivo" concretizado a partir de ligações diretas a unidades curriculares do primeiro ciclo, a definir, anualmente, com supervisão das coordenações/direções dos cursos (Coelho, 2015: 533).

Entre os académicos e jornalistas que participam no debate do Labform impõe-se como instrumento de aproximação determinante a participação de jornalistas profissionais no ativo, ou antigos profissionais, "em seminários ou conferências" (Adelino Gomes), ou mesmo, como defendem Carla Baptista, da UNL, e Duarte Valente, jornalista da RTP, a integração formal de jornalistas na docência. Carla Baptista sugere que o envolvimento desses profissionais seja extensível a "todos os ciclos de estudo". 
Carlos Camponez, da Universidade de Coimbra, defende, por seu lado, aquilo que poderíamos classificar como uma corrente contínua entre jornalistas e académicos, ambas as partes promovendo a troca de experiências em debates, visitas e intercâmbios. Maria Miguel Cabo, jornalista da SIC, e Adelino Gomes, jornalista e investigador, estendem esse intercâmbio aos alunos, promovendo, durante o primeiro ciclo, a participação destes em colóquios, fóruns, debates e trabalhos práticos. Carlos Rico sublinha que o processo gradual de aproximação do aluno à profissão é uma batalha longa. 0 jornalista da SIC inclui no redesenho dessa incursão a realização de "encontros informais" dos alunos com os principais agentes da profissão: jornalistas, empresários, responsáveis pelos departamentos comerciais das empresas, dirigentes do Sindicato dos Jornalistas, membros do Conselho Deontológico, responsáveis da ERC, etc".

Para Carla Baptista, a aproximação entre os dois mundos requer alterações ao nível do próprio plano de estudos, a dois níveis: por um lado, "desenvolvendo unidades curriculares voltadas para a prática jornalística", por outro "estabelecendo parcerias ao nível da investigação e da produção de conteúdos jornalísticos semiprofissionais". Inês Amaral, da Universidade do Minho, propõe a reclassificação dessas unidades curriculares voltadas para a prática, introduzindo o conceito de laboratório - unidades promotoras de "uma prática reflexiva da teoria", nos moldes em que nós próprios as definimos, assumindo-as "lugar privilegiado de interseção entre teoria e prática":

"Neste contexto, as aulas em laboratório devem ser assumidas por docentes com diversas competências, que incentivem os alunos a desenvolver trabalhos específicos (jornalísticos ou académicos) promotores dessa articulação teoria-prática" (Coelho, 2015: 528).

Vai em sentido diferente a proposta subscrita por Carlos Rico. 0 jornalista da SIC defende a substituição das "tradicionais salas de aula" por "ambientes de redação", onde "a organização interna replique os modelos mais frequentes de editorias, secções, produção, agenda, etc". A proposta de "aprender fazendo", sentindo a "pressão do tempo" e seguindo, como sugere o jornalista, a dinâmica do quotidiano profissional, consubstancia, em nosso entender, a transformação da sala de aula numa antecâmara da redação, perdendo-se, por essa via, a própria matriz académica, onde a valorização da reflexão permite apelar a saberes apreendidos no tronco comum e no curso. Essa articulação com quadros concetuais mais abrangentes é determinante para o jornalismo e deve ser integralmente subscrita, desde logo, no decurso do processo de formação do aluno.

\section{A Formação Académica Impôs-se como Via de Acesso Natural: um Debate em Curso no Labform}

0 grau de complexidade intelectual associado à ação quotidiana cria uma certa unidade de pensamento entre académicos, jornalistas e empresários, impondo a formação académica na área como a principal via de acesso à profissão (Coelho, 2015: 281). Todavia, se é certo que as empresas, detetando na academia uma fon- 
te de produção de mão-de-obra barata (Meyer, 2004: 232), se demitiram da tarefa de formar de raiz os novos recrutas (Coelho, 2015: 268) é igualmente verdade que a academia assume, com algum grau de desconforto, a forma como essa missão Ihe é reclamada. Afinal, como salienta Cole, "os padrões académicos" exigem que o ensino universitário "ultrapasse o mero treino vocacional" (2003:59), exigido pelas empresas.

As divergências de opinião não diminuem, contudo, o peso crescente da academia no acesso à profissão. Deixou de estar, pois, em causa a necessidade de uma formação académica específica, para que a discussão se centre no modelo, na matriz, dessa formação.

Carlos Camponez considera mesmo "gongórica" a discussão em torno da necessidade de uma formação académica especializada. Para o docente da Universidade de Coimbra, a conclusão de um percurso académico na área "é uma exigência ética de uma profissão com um forte pendor de serviço público".

Aníbal Alves reconhece que as especificidades associadas ao jornalismo revelam alguma "dificuldade e incerteza" quando queremos aplicar o princípio geral associado às profissões clássicas, que classifica a formação académica como determinante "na preparação para o exercício competente de uma especialidade profissional de nível superior, quer de carácter científico, quer de carácter humano e social". 0 Professor Emérito da Universidade do Minho questiona sobretudo a relevância desse princípio das profissões clássicas ante 0 vasto quadro de competências profissionais e intelectuais requeridas ao jornalista, mas reconhece que a forma como a formação académica especializada se impôs - "0 apelo e convicção atingiram tal vigor" - que a necessidade desses cursos se tornou evidente.

No Labform, da discussão sobre o modelo de formação vão saindo lugares de amplo consenso que, no essencial, assumem a formação académica como a base de um processo que deve ter continuidade na redação, que, como sustenta Joaquim Fidalgo, sucede em todas as profissões:

"A formação total de um jornalista estará sempre incompleta se se restringir à formação académica. Mesmo que esta inclua uma alargada componente prática, há muita coisa prática que só se aprende com a experiência em contextos profissionais - e em contacto directo, activo, quotidiano, com outros profissionais".

O lugar privilegiado da academia e dos cursos de jornalismo/comunicação é, pois, o lugar da reflexão. Como reconhece Fidalgo, a formação académica impõe-se, por isso, no domínio do ser, mais do que no do fazer:

"Mais do que ensinar a "fazer jornalismo", no sentido de "praticar actos de jornalismo" - algo hoje em dia perfeitamente acessível a qualquer mortal com um mínimo de espírito de observação e dois dedos de testa -, um curso superior deve contribuir para se aprender a "ser jornalista". " E isso ensina-se olhando à volta, com olhar crítico, o que é hoje e como funciona o jornalismo, para o bem e para 0 mal. Ensina-se reflectindo sobre o papel que tem ou não tem (e pode ou não pode, e deve ou não deve ter) o jornalismo nos nossos dias. Como dizia alguém para os 
professores de uma escola de Jornalismo: "Ensinem-nos a pensar, a pensar bem, que nós depois ensinamos-lhes rapidamente as técnicas...".

As técnicas profissionais apreendem-se de forma direta e imediata, estão sujeitas ao treino, ao aprimoramento das rotinas. Devem ser trabalhadas e exploradas na academia mas, como atrás referíamos, ancoradas no primado da reflexão. Como salienta Sonia Lamy, trata-se de "discutir, debater e pensar o jornalismo", algo que a docente da Escola Superior de Educação de Portalegre considera "absolutamente necessário ao exercício de uma profissão tão complexa e determinante numa sociedade democrática".

\section{Uma Dispersão de Saberes em vez de um Modelo Comum}

Ultrapassada a questão da necessidade da formação, o passo que se impõe é a discussão do modelo de formação. 0 que se afigura complexo é a dispersão intelectual que reina entre a comunidade académica associada à área, expressa na viagem que fizemos pelos programas de formação que analisámos na nossa investigação de doutoramento.

É certo que a complexidade do jornalismo atual exige dos programas de estudo a adoção de uma confluência de saberes, em direção a um lugar de reunião, de comunhão, ou, como refere Manuel Pinto, a uma abrangência "ecuménica":

"um concerto de dimensões, em que os vários naipes - filosofia, sociologia, cultura, política, linguagem, comunicação, tecnologia, estudos jornalísticos - encontrem modo de se articularem entre si" (2004: 60).

A assunção desse princípio não deve, todavia, distanciar-nos da realidade, mormente da vastidão de saberes impregnada nos múltiplos planos de formação em vigor. De facto, o problema coloca-se quando a abrangência de saberes e competências requeridos pressupõe a delimitação de um trajeto de formação. Nesse ponto, a via de acesso transforma-se numa estrada aberta à vastidão das ciências sociais e humanas, à comunicação, aos estudos jornalísticos e, nalguns casos, à matemática e à estatística; uma amplitude ingerível, que impossibilita a definição de um saber mínimo comum, que possa fechar o ângulo desta formação enciclopédica.

Impõe-se, assim, um processo de depuração das matérias que realmente devem participar na estruturação do modelo de formação. Colocado no centro do plano de estudos, o campo da comunicação sobressai como filtro (síntese) que recebe as influências dos campos vizinhos, adaptando-as à sua própria génese e disponibilizando-se para transportar o resultado das interseções intelectuais para o subcampo profissional.

A missão depuradora da comunicação, que propomos, é, afinal, o estabelecimento da ordem no caos. Nos anos 60 do século passado, como assinala Carlos Camponez, a comunicação "era como uma encruzilhada em que todos passavam e ninguém se detinha". 0 docente da Universidade de Coimbra, consciente da centralidade da comunicação nos programas de estudo na área, aponta como desiderato desses programas de estudo, que constitui, afinal, a sua razão de ser, a organização desses "saberes essenciais que atravessam a encruzilhada da comunicação". 
Neste sentido, tecnologia, o instrumento que promove e amplia a comunicação, e a estatística, que ajuda o jornalismo a interpretar e a elaborar quadros concetuais de apreensão da realidade, constituirão um outro nível, meramente instrumental, dentro do plano curricular, jamais funcionando desarticulado das necessidades momentâneas da profissão. Ou seja, são complementos essenciais à ação profissional, mas não constituem, elas próprias, elementos estruturadores da ação profissional.

Ora aquilo a que hoje assistimos é a uma dispersão absoluta de saberes, sem nenhum ponto de ordem a uni-los.

Para confirmarmos a distância entre os projetos formativos na área basta-nos detalhar os programas dos dois cursos da universidade pública, que analisámos na nossa investigação de doutoramento, o curso da Universidade Nova de Lisboa e 0 curso da Universidade do Porto. A média elevada que, anualmente, condiciona 0 acesso a estes dois projetos formativos é o elemento comum que os une; mas será 0 único. 0 curso da UNL reflete um distanciamento das profissões da comunicação em geral e do jornalismo em particular, limitando a oferta curricular profissional aos 30 créditos da variante e a 12 que integram o tronco comum. 0 curso da UP integra 110 créditos profissionais no plano de estudos, mais de 60 por cento do total do percurso formativo. A aposta do curso da UP na vertente multimedia e tecnológica não tem qualquer expressão no plano de estudos do curso da UNL. São ambos cursos de Ciências da Comunicação com vertente de Jornalismo.

É certo que o jornalismo reclama um grau de abrangência de saberes e competências, mas, certamente que algumas das matérias da enciclopédia serão mais decisivas do que outras. Esta vasta amplitude de base corre o risco de tornar indistinta a formação específica, colocando-a, no momento do acesso à profissão, ao nível de outros percursos formativos da área das ciências sociais e humanas ${ }^{5}$.

\section{A Consolidação de um Saber Mínimo Comum}

A nossa proposta assume, por isso, um caminho em direção à definição de um saber mínimo, mas que salvaguarde a abrangência do jornalismo. Esse compromisso resulta de um conjunto de premissas:

- A estreita interligação entre os cursos da área ministrados no ensino politécnico e universitário é um sinal de salvaguarda da abrangência reclamada pelo jornalismo. Essa articulação pressupõe a existência de cursos com a mesma matriz de base (a comunicação), mas onde a aproximação e a ligação à profissão obedeçam a diferentes ritmos. Um aluno que optar pelo politécnico sabe que estará a investir num projeto formativo que lhe permite responder às necessidades imediatas da profissão, simultaneamente dominando as técnicas essenciais ao desempenho quotidiano, mas municiado das ferramentas analíticas que atribuam significado a essa ação. 0 aluno que escolher o percurso universitário terá de articular, preferencialmente, o primeiro ciclo com o segundo ciclo. No primeiro ciclo adquirirá competências sobretudo reflexivas, que lhe permitirão agir sobre o jornalismo com o propósito de participar

5 Esta posição é assumida por alguns dos autores cujos depoimentos coligimos e colocámos no Labform, coincidindo, também, com outras já divulgadas no nosso trabalho de doutoramento. 
na melhoria da sua prática. 0 contacto com a técnica profissional ocorrerá, apenas, no último semestre do primeiro ciclo, ainda assim, em interligação permanente com a componente reflexiva. A aquisição de competências profissionais acontecerá, então, no segundo ciclo, onde 0 aluno poderá testar abordagens inovadoras e alternativas e aplicar os conhecimentos adquiridos ao longo do percurso.

- Os cursos universitários e politécnicos estabelecem a comunicação como eixo central do plano de estudos, mas o papel que esta exerce, em cada um deles, é diferente. No caso dos cursos politécnicos, a comunicação associa-se diretamente à prática profissional, atribuindo-Ihe significado; nos cursos universitários, a comunicação produz a síntese das influências das humanidades e das ciências sociais e transporta esses resultados para a variante profissional, tornando-a mais reflexiva.

- Nos cursos universitários, que constituem a base da nossa proposta, a equiparação da variante ao tronco comum reduz, desde logo, o grau de dispersão normalmente associado ao tronco comum;

- A variante não se restringe às unidades curriculares profissionais. A sua base é, aliás, a interligação entre a profissão e a comunicação, o eixo síntese que convoca as áreas de saber que mais diretamente auxiliam o jornalista a ultrapassar os constrangimentos impostos pelo mercado; resistindo-Ihes, mas consciente de que deve servi-lo.

A profissão que reclama saberes e competências diversos é, todavia, exercida quotidianamente fazendo uso de um conjunto limitado de técnicas, que apelam à prescrição de receitas práticas quase universais, que tornam o jornalismo cada vez mais igual, independentemente dos meios, das gerações envolvidas, dos países. Esta matriz, regulada pela abrangência do mercado, limita o alcance do jornalismo. Sem exigir um quadro concetual que lhe dê enquadramento, a prática jornalística quotidiana fica, assim, na dependência direta de uma entidade abstrata, superior, que a comanda.

A base de um programa comum de formação deve questionar essa entidade abstrata, promover abordagens alternativas inovadoras que protejam o jornalismo, tornando-o cada vez mais útil, relevante e decisivo.

Enquadrada a definição de um saber mínimo de acesso à profissão, cabe-nos assumir, sem reservas, que o jornalismo deve ser exercido, exclusivamente ${ }^{6}$, por licenciados em jornalismo/comunicação. Essa decisão decorre da aliança estratégica entre jornalismo e academia e, a sua aplicação, constitui o sustentáculo do processo de reconstrução. A proposta que defendemos, cujas linhas gerais aqui apresentámos, é o nosso contributo para o debate.

6 Admitimos a possibilidade de licenciados noutras áreas poderem integrar a profissão, mas defendemos que essa formação de base, fora da comunicação/jornalismo, seja complementada com estudos de segundo ciclo no campo específico do jornalismo. 


\section{Bibliografia}

Coelho, Pedro, 2015a, Jornalismo e Mercado, os novos desafios colocados à formação, Covilhã, UBI, Livros LABCOM.

Coelho, Pedro, 2015b, "Jornalismo e Comunicação: Contributos para a Estruturação de um Novo Modelo de Formação", in Aprender, Revista da Escola Superior de Educação de Portalegre, n. ${ }^{0} 35$.

Cole, Peter, 2003, "The media training jungle", vol. 14, n. ${ }^{0} 1$, ("British Journalism Review"), 54-60.

Dorer, J., 2003, "The Historical Development and Present State of Journalism Trainig in Austria", R. Fröhlich e C. Holtz-Bacha (org.), Journalism Education in Europe and North America - an International Comparison. The Hampton Press Communication Series - Mass Communication and Journalism, New Jersey, Hampton Press237-255.

Garcia, José Luís; (org.), 2009, Estudos sobre os Jornalistas Portugueses. Metamorfoses e encruzilhadas no limiar do séc. XXI, Lisboa: Imprensa de Ciências Sociais.

Gomes, Adelino, 2012, Nos bastidores dos telejornais, Lisboa, Tinta da China.

Meditsch, Eduardo, 2004, "A formação para a praxis profissional do jornalista: uma experiência inspirada em Paulo Freire", n. ${ }^{0}$ 5, ("0 Ensino do Jornalismo, Revista Comunicação e Sociedade"), 25-38.

Meyer, Philip, 2004, The Vanishing Newspaper, saving journalism in the information age, University of Missouri Press.

Pinto, Manuel, 2004, "0 ensino e a formação na área do jornalismo em Portugal: crise de crescimento e notas programáticas", n. ${ }^{0} 5$, ("0 Ensino do Jornalismo, Comunicação e Sociedade"), 49-62.

Rebelo, José (org.), 2011, Ser Jornalista em Portugal. Perfis Sociológicos. Lisboa, Gradiva.

Reese, Stephen D., 1999, "The progressive potential of journalism education: recasting the academic versus professional debate", vol. 4, n. ${ }^{0} 4$, ("The International Journal of Press/ Politics"), 70-94.

Zelizer, Barbie, 2004, Taking journalism seriously, news and the academy, Londres, Sage. 